\title{
Learning About Oxytocin: Pharmacologic and Behavioral Issues
}

\author{
Bice Chini, Marianna Leonzino, Daniela Braida, and Mariaelvina Sala
}

Despite the accumulating evidence suggesting that the neuropeptide oxytocin (OT) plays a role in neuropsychiatric disorders characterized by social dysfunction, the influence of OT on the nonsocial aspects of learning and memory have been less investigated. To foster research in this area, we review the effects of OT on learning and memory in animal models and humans. In healthy animal models, OT improves memory consolidation and extinction, but only if given at a low dose immediately after the acquisition phase. On the contrary, OT effects in healthy humans have been inconsistent; although, in this case, OT was always given before the acquisition phase and no dose-response curves have ever been drawn up. Interestingly, a specific impairment in the reversal of learning has been found in mice devoid of OT receptors and OT has been demonstrated to enhance fear extinction in rodents. All together, these data suggest that OT plays a role in elementary forms of behavioral flexibility and adaptive responses and support its therapeutic potential in neuropsychiatric disorders characterized by cognitive inflexibility and/or impairment (autism, schizophrenia, Alzheimer's disease, Parkinson disease, stroke, posttraumatic stress disorder). Accordingly, OT has been shown to improve cognitive flexibility in OT receptordeficient mice, and scattered findings indicate that intranasal OT has positive effects on the memory of patients with schizophrenia or posttraumatic stress disorders. Further studies of the therapeutic potential of OT as an enhancer of learning and memory are warranted.

Key Words: Animal models, consolidation, flexibility, learning and memory, neuropeptide, neuropsychiatric disorders, oxytocin

$\mathrm{T}$ his review will concentrate on aspects of learning and memory other than social behavior and social cognition, because the involvement of oxytocin (OT) in shaping and regulating the social brain have been extensively covered by a number of excellent and exhaustive reviews (1-4). It first reviews experimental data relating to learning and memory paradigms in animal and humans and then summarizes what is known about its neurochemical substrates in rodents. Finally, it discusses a few critical issues in the hope of encouraging the successful therapeutic use of OT in neuropsychiatric disorders.

\section{Oxytocin in Learning and Memory}

\section{Animal Studies}

Table 1 and Tables S1 and S2 in Supplement 1 provide a comprehensive overview of all of the reviewed papers describing the administration of OT to animal models (mainly rodents, but also birds and molluscs). Table 1 shows the studies reporting enhanced learning and memory (5-10), while Table S1 and Table S2, respectively, in Supplement 1 show the studies reporting impaired learning and memory $(6,11-21)$ or no effect $(10,13,15,22-27)$. Most papers consider the effects of OT on learning and memory in mice and rats, but findings in elderly monkeys indicate that OT (4-128 $\mu \mathrm{g} / \mathrm{kg})$ subcutaneously (SC) administered 30 minutes before the task impaired memory in three of the six but led to subtle but replicable improvements in the number of correct choices in two monkeys (28). It is surprising that there are no data concerning memory (other than social

From the National Research Council (BC, ML, MS), Institute of Neuroscience; Dipartimento di Biotecnologie Mediche e Medicina Traslazionale (ML, DB, MS), Università degli Studi di Milano; and Fondazione Istituto di Ricovero e Cura a Carattere Scientifico Don Gnocchi (DB), Milan, Italy.

Address correspondence to Mariaelvina Sala, Università degli Studi di Milano, Dipartimento di Biotecnologie Mediche e Medicina Traslazionale, Via Vanvitelli 32, Milano 20129, Italy; E-mail: mariaelvina.sala@unimi.it. Received Mar 20, 2013; revised Jul 10, 2013; accepted Aug 18, 2013. memory) in prairie and mountain voles (Microtus ochrogaster), which are among the most widely used models for investigating the biological roots of mating and other social behaviors (29). Furthermore, although few data are available concerning other species, the findings in birds (pigeons and chicks) and molluscs (Sepia officinalis) are in line with those of rodents. These studies have led to the development of a vasopressin (AVP)/OT central memory theory that suggests AVP enhances and OT inhibits memory consolidation and retrieval. However, the exact involvement of these molecules in learning and memory is still very controversial (30), mainly because the experiments have used different doses and administration routes. Furthermore, learning and memory processes involve many distinct phenomena that can be distinguished on the basis of the stimulus (spatial, aversive, or rewarding), context (nonsocial, social), and/or timing (acquisition, consolidation, retention, extinction, recall).

Dosage. As has often been observed in behavioral studies, the dose-response curves of OT's effects have an inverted-U shape. In mice and rats, a moderate OT dose (100-300 ng/kg) impairs passive avoidance, whereas lower (10 or $30 \mathrm{ng} / \mathrm{kg}$ ) or higher doses $(1000 \mathrm{ng} / \mathrm{kg})$ have no effect $(13,16)$. Similarly, the extinction phase of pole-jumping behavior is inhibited by high SC doses of OT (1000-3000 ng per rat) given during consolidation, whereas lower doses $(<1000 \mathrm{ng})$ have no effect or tend to facilitate extinction (6). Oxytocin has a biphasic effect on social behavior: very low peripheral doses (in the $\mathrm{pg}-\mathrm{ng} / \mathrm{kg}$ range) improve social memory but higher $(\mu \mathrm{g}-\mathrm{mg} / \mathrm{kg}$ ) doses disrupt it (31-35). Finally, the intracerebroventricular (ICV) administration of the selective OT agonist [Thr4,Gly7]-oxytocin to Oxtr ${ }^{+/-}$mice improves social recognition deficit at a dose of $.0005 \mathrm{ng} /$ mouse, whereas higher doses (.005-.5 ng/mouse) and a lower dose (.00005 ng/mouse) do not (35). The U-shaped, biphasic, or even more complex doseresponse curves may be due to various factors. High doses of OT may activate AVP V1a and/or V1b receptors, as observed in Oxtr ${ }^{-/}$ and $\mathrm{Oxtr}^{+/-}$mice $(36,37)$, and the release of other neurotransmitter/hormone systems may be modulated. When given before extinction, OT delays fear conditioning extinction in rats in a bimodal manner, depending on the levels of corticosterone released (16), whereas AVP has no significant effect on the corticosterone response to noise stress (38). Finally, some of the studies cited above used very high doses of OT peripherally 
Table 1. Improving Effect of OT on Memory in Different Tasks

\begin{tabular}{|c|c|c|c|c|c|}
\hline Species & Route & Dose & Test & $\begin{array}{c}\text { Affected } \\
\text { Memory Phase }\end{array}$ & Reference \\
\hline Male Mice & SC & $.1 \mathrm{ng} / \mathrm{kg}$ & Novel object recognition & Consolidation & (5) \\
\hline Rats & SC & $.01 \mathrm{ng}$ & Passive avoidance & Consolidation & (6) \\
\hline Sepia Officinalis & Peripheral & $3000-60000 \mathrm{ng} / \mathrm{kg}$ & Passive avoidance & Consolidation & (7) \\
\hline Chicks & Intracerebral & $5 \mathrm{pg}-50 \mathrm{ng}$ & Conditioned taste aversion & Consolidation & (8) \\
\hline Wistar Rats & DSN & $.05 \mathrm{ng}$ & Passive avoidance & Consolidation & (9) \\
\hline Virgin Female Mice & ICV & $2 \mathrm{ng}$ for 12 days & Radial maze & Long-term memory & (10) \\
\hline
\end{tabular}

DSN, dorsal septal nuclei; ICV, intracerebroventricular; OT, oxytocin; SC, subcutaneous.

(Table S1 and Table S2 in Supplement 1) without considering the risk of interfering with overall behavioral performance, whose integrity is essential in all memory paradigms. In this regard, it has been reported that a very high peripheral dose of $3000 \mathrm{ng}$ per rat significantly reduces all measures of general activity (6), as confirmed by our unpublished data indicating that $1 \mathrm{ng}$ per mouse ICV reduces general arousal. The effective dose on any specific behavioral parameter should be experimentally ruled out on the basis of carefully planned dose-response curves.

Administration Routes. Two important issues that need to be clarified is whether peripherally administered OT reaches the brain because of its very limited passage through the blood/brain barrier (BBB) (39), and the brain OT levels required to have a mnemonic effect. Small amounts of OT may cross the BBB (40), and it has been calculated that $.002 \%$ of SC or intravenous OT reaches the cerebrospinal fluid (CSF) of freely moving rats within 10 minutes of administration. However, after 30 years of research, there is still no irrefutable proof that peripherally administered OT (and related peptides) actually does cross the BBB: for example, there is intense controversy as to whether this is true of intranasally administered OT and AVP, and two papers reported conflicting results in the space of 2 months in 2013 (41,42). However, although the mechanisms by which peripherally administered OT acts within the brain are not known, there is no doubt that central effects are observed after intranasal, SC, and intravenous administration in various animal species. Animal studies of the intranasal route (the preferred route in humans) have only considered social behavior, but it is interesting to note that $25 \mathrm{IU}$ of OT intranasally administered to rhesus macaques increased the frequency of prosocial choices associated with reward to another monkey 2 hours after inhalation (43), and in the same study, CSF OT levels doubled within 35 minutes (43), thus supporting the idea that endogenous OT in the CSF comes from central and not peripheral sources. In prairie voles, the acute effects of intranasal OT resemble those found in many human studies (an increase in prosocial behavior and engagement), but when given for 21 days at three doses $(.08, .8$ or $8.0 \mathrm{lU} / \mathrm{kg})$, it impaired the formation of pair-bond behavior (44) and this detrimental social consequence persisted far longer than the treatments themselves.

It is very difficult to estimate the brain OT levels required to have an effect on memory. It has been shown that an ICV injection of $1 \mathrm{pg}$ can begin to restore social memory deficit in $\mathrm{Oxt}^{-1-}$ mice, although better results are obtained using $1 \mathrm{ng}$ (45). Accordingly, a very low SC dose $(.1 \mathrm{ng} / \mathrm{kg})$ improves the consolidation of episodic memory in mice engaged in the object recognition task (5). Unfortunately, no data are available concerning OT levels during memory tasks.
Learning Paradigms and Phases of Memory. An important finding is that OT does not appear to play a key role in spatial learning because the acquisition phase of spatial memory is not impaired in $\mathrm{Oxt}^{-1-}$ mice evaluated using the Morris water or a two-trial Y-maze (46), and Oxtr ${ }^{-1-}$ mice and their wild-type littermates have similar spatial memory acquisition rates when performing an appetitive-motivated T-maze task (36). Accordingly, repeated injections of OT (2 ng ICV for 12 days) do not impair short-term memory in virgin female mice undergoing a radial maze task (10). However, in the same experimental setting, OT significantly improves long-term memory, thus suggesting it enhances consolidation, a central attribute of hippocampal function to which OT and AVP may contribute (47). Consolidation is the processes of stabilizing a memory trace after initial acquisition and consists of two specific phases: synaptic consolidation (within the first few hours of learning or encoding) and system consolidation, during which hippocampus-dependent memories become independent of the hippocampus over a period of weeks or years. Retrieval and extinction are two other strictly connected processes associated with consolidation: retrieval is the only way memory can be measured, and extinction is the process by which a conditioned response diminishes over time. To determine whether a drug is involved in consolidation or retrieval, it can be administered before or after different phases of training and/or testing. A careful examination of the few published reports indicates that OT can improve memory but only under certain conditions (Table 1): a low dose given immediately (or at most 1 hour) after the acquisition phase $(5,9,10)$. Similarly, a very low SC OT dose $(.1 \mathrm{ng} / \mathrm{kg})$ given to mice performing the object recognition task improves the consolidation of episodic memory, and this effect is antagonized by a selective oxytocin receptor (OTR) antagonist (5). In the wake of findings regarding the enhancing effects of OT-like peptides on memory consolidation, a recent study of Sepia officinalis, a cephalopod mollusc known for its remarkable learning abilities, showed that a peripheral injection of cephalotocin (an OT analogue) 1 hour after training facilitated long-term memory in a passive avoidance task (7). Accordingly, intracerebral administration of OT (5 pg$50 \mathrm{ng} /$ animal) to chicks enhances retention in a dose- and timedependent manner, with $5 \mathrm{ng}$ being the best dose when given 1 minute after acquisition (8).

Other forms of memory are improved by OT if the above parameters are followed. For example, OT enhances memory in the passive avoidance task when injected 30 minutes after learning into the lateral septum of rats but not when injected into other brain areas (Table S3 in Supplement 1) (9). The septum is one major brain structure in which endogenous OT and AVP exert their behavioral effects $(30,48)$ : it receives OT and AVP fibers originating from the bed nucleus of the stria terminalis and the 
amygdala (49) and contains OT and AVP receptors (50-52). The septal region also contributes to reference memory, particularly the encoding and consolidation of information and/or its subsequent recall (53). Finally, intraseptal OT facilitates social recognition in rats (54). When acutely administered after acquisition, OT facilitates fear extinction in a fear conditioning test (55), although the very high ICV doses used ( $1 \mu \mathrm{g}$ per rat) do not exclude the participation of arginine vasopressin receptor 1 subtype a/ arginine vasopressin receptor 1 subtype b (V1aR/V1bR).

Response inhibition and extinction learning can also be considered elementary elements of behavioral flexibility, a set of strategies aimed at assuring successful performance in unfixed and challenging environments. Tests of behavioral flexibility in mice are represented by reversal learning and set shifting, in which a previously learned response or rule needs to be suppressed to redirect attention to a previously irrelevant stimulus or stimulus dimension. It is worth noting that $\mathrm{Oxtr}^{-/-}$mice are impaired in the reversal phase of an appetitively motivated T-maze test, whereas $\mathrm{Oxtr}^{+/+}$(37) or Oxtr $^{+/-}$mice are not (36). Such impairments can be due to perseveration or a reduced ability to acquire or maintain a new strategy. Given the relevance of perseveration and behavioral rigidity to human psychopathology, we believe that the role of OT in behavioral flexibility merits particular attention. It is also worth noting that $\mathrm{Oxtr}^{+/-}$mice, which express only $50 \%$ of brain OTRs (36), show impaired sociability but normal cognitive flexibility and are not aggressive, thus indicating that the number of OTRs affects these phenotypical manifestations. In addition to OT release, the level of OTR expression in the brain may be a key factor in determining OTmediated behaviors.

A functional AVP/OT-like signaling system has been found in the nematode Caenorhabditis elegans. Mutants worms lacking nematocin (an AVP/OT-related neuropeptide) or its receptor were subjected to an associative learning paradigm using a short-term gustatory plasticity assay (56). The results suggested that defects in the nematocin signaling cascade disrupted gustatory associative learning and the facilitated experience-driven modulation of sodium chloride chemotaxis. Although there are few comparative data, the findings described above indicate that the effects of OT on memory are similar in different species.

\section{Human Studies}

In humans, OT has been preferentially administered intranasally, but different studies are difficult to compare for various reasons: the limited dose range, single versus repeated administrations, and the use of different cognitive tasks.

The studies based on nonsocial stimuli (e.g., words) have found a memory-impairing effect or none at all. A very low dose of OT (.038 IU) had inconsistent effects on memory and mood functions in healthy male volunteers when evaluated 1 hour after treatment by means of attentional and visual analogue scales tests (57). Higher and repeated doses (15 IU three times a day for 50 days) did not affect the learning of a word list but impaired subsequent recall in six healthy subjects, a transient effect that was the opposite to that induced by AVP (58). Similar results were obtained in another study (59) in which the subjects received nasal sprays of OT (40 $\mu$, corresponding to $24 \mathrm{IU}) 1,24$, or 48 hours before the acquisition phase of a memory test. The impairing effect of OT on the long-term memory of healthy subjects (evaluated by the free recall of verbal memory) has been confirmed by a study in which OT $(40 \mu \mathrm{g})$ was administered 10 minutes before acquisition (60).
Various memory tests have been carried out in human healthy subjects using social (reproduction-related words associated with gender or faces) or nonsocial stimuli (a list of words, houses, or neutral pictures). The administration of OT 24 IU 40 to 50 minutes before the acquisition phase had no effect (61-63) or impaired (64) the recall of nonsocial stimuli but impaired or improved the recall of social stimuli: this difference could only be partially explained by differences in the types of faces (neutral versus emotional) or objects (houses versus sculptures and landscapes).

Apart from the study using the very low dose of .038 IU (57), none of the human studies have used doses other than the usual 15 to $24 \mathrm{IU}$, and this has prevented the construction of a doseresponse curve. However, as animal studies suggest that the effects of OT are dose-dependent, studies directly comparing more than one dose (and preferably a range of doses) would be useful. Furthermore, as OT improves memory in animals when given within 1 hour of acquisition, it would be interesting to investigate the human effects of OT during the consolidation phase.

One open question is how long brain OT levels remain elevated after intranasal administration. It has been shown that CSF levels of the cognate peptide AVP increase for up to 80 minutes and remain above baseline levels for 100 to 120 minutes (65). However, there are no data concerning OT itself. It is worth noting that no convincing evidence of a direct correlation between central and peripheral OT levels has been reported in humans, which suggests caution when interpreting associations between peripheral levels and psychiatric conditions. Furthermore, the lack in reliability of commercially available methods for OT determination raises serious concerns about their validity $(66,67)$.

Although accumulating evidence suggests that OT plays a role in many neuropsychiatric disorders (particularly those involving social dysfunction, such as autism spectrum disorders, social anxiety disorders, obsessive-compulsive disorders, attachment disorders, depression, and schizophrenia), its therapeutic potential is still intensely debated (68). Cognitive deficits are a prominent and disabling component of schizophrenia, and the efficacy of current pharmacologic treatments is limited. Plasma OT concentrations are lower in schizophrenic patients than in normal subjects and negatively correlate with psychotic symptoms $(69,70)$. The first evidence of the beneficial effect of OT on memory comes from a small group of schizophrenic patients treated with intranasal OT (20 IU) twice a day for 1 week and then with 40 IU twice a day for a further 2 weeks (71), who showed a striking improvement in short-term but not long-term verbal memory as assessed by the California Verbal Learning Test and the Letter Number Sequence. In an another study (72), intranasal OT (24 IU) twice daily for 14 days reduced the effects of psychotic symptoms and improved social cognition in schizophrenic patients. However, it is currently impossible to discern how much of the beneficial effect of OT on verbal memory is due to specific procognitive effects and how much is secondary to the OTinduced reduction in the patients' core schizophrenia symptoms. Nevertheless, although the use of different cognitive tests makes it difficult to compare the studies, the positive results appear promising.

Few studies have reported brain OT system alterations in aging subjects or those with degenerative neurological disorders (of which memory disturbances are a clinical hallmark). Studies of rats (73) and monkeys (74) have found an age-related decrease in central OTergic activity, but no human data are available. Postmortem studies of brain tissue taken from elderly subjects 
affected by Alzheimer's disease have led to mixed findings of decreased (75), increased (76), or unchanged OTergic activity (77), thus leaving the field open to further investigation.

Oxytocin may have a beneficial effect on posttraumatic stress disorder (PTSD). The memory impairments associated with PTSD may be related to functional and morphological changes in the brain structures involved in episodic memory function, including the frontal cortex, hippocampus, and amygdala (78). An enhancing role of OT in extinction is consistent with the finding that the intranasal administration of OT (48 IU) inhibited memory retrieval in 43 male veterans of the Vietnam war with PTSD (79). A very recent study (80) involved 44 healthy subjects who underwent a conditioned fear acquisition procedure before receiving acute treatment with OT (24 IU); 45 minutes later, they underwent extinction training and they were tested for extinction recall after a further 24 hours. It was found that OT facilitated extinction recall, which supports its potential use as adjunctive treatment to extinction-based therapies for fear-related disorders.

Although preliminary clinical trial results indicate that OT is beneficial in schizophrenic patients, much work is still needed to advance its therapeutic development in other neuropsychiatric or neurological disorders.

\section{The Neurochemical Substrates of OT-Induced Effects on Learning and Memory}

Although it has been clearly established that OT plays a role in learning and memory in animal models, the cellular and molecular mechanism(s) underlying its action are much less well known. Oxytocin can influence learning and memory at different times and in different ways (by establishing neural networks during development, by cooperating with classical neurotransmitter systems, and by directly mediating plasticity phenomena in target neurons), and animal studies are beginning to provide some clues concerning these substrates, particularly at neurochemical and electrophysiological levels.

There is virtually no OT immunoreactivity in the developing brain (81), and the first exposure to OT occurs perinatally or postnatally. Interestingly, some evidence indicates that OT plays both neuroprotective and neurodevelopmental roles in the postnatal period. At about the time of delivery, it temporarily switches gamma-aminobutyric acid (GABA) neurotransmission from its excitatory to its inhibitory form, thus potentially protecting hippocampal neurons from anoxic insults (82); this protective effect on immature cultured hippocampal neurons has recently been confirmed by an oxygen/glucose deprivation challenge (83). It has also been elegantly shown that OT triggers the appearance of the coherent activity pattern in the developing hippocampus (84), thus suggesting that it plays a role in the maturation of neuronal microcircuits. Data showing an imbalance in GABA/ glutamate synaptic contacts in cultured postnatal hippocampal neurons obtained from $\mathrm{Oxtr}^{-1-}$ mice (37) also support the possibility that OT plays a role in regulating GABA signaling at the end of the second postnatal week, in concomitance with the final shift of GABA from depolarization to hyperpolarization (85).

The contribution of OT to the formation of new connections and synaptic contacts may also influence learning and memory processes in the mature brain. An OT-induced improvement in hippocampus-dependent plasticity has been described in motherhood (10), and this is in line with accumulating evidence that late pregnant and lactating rats have denser populations of hippocampal dendritic spines than virgins and that maternal experience alters hippocampal plasticity to ensure the better care of the pups (86). It is also worth mentioning that OT stimulation of neurogenesis has been found in adult rat hippocampus (87). Finally, functional magnetic resonance imaging studies have started to shed light on the OT-induced modulation of functional connectivity in the human brain, as extensively reviewed elsewhere (88).

A number of studies of the effect of OT on basal neurotransmission in adult hippocampus have found an inhibitory action mediated by the activation of GABAergic interneurons (89-92), and a few studies have also found that OT acts on activity-dependent hippocampal synaptic plasticity. In the medial prefrontal cortex, OT converts long-term depression to long-term potentiation (LTP) (93), and in the cornu ammonis 1 (CA1) pyramidal neurons of adult rats, it prolongs the duration of LTP $(10,94)$. Surprisingly, this latter finding was obtained in the dorsal hippocampus of male and female rats aged 4 to 5 weeks, a region in which no OT fibers have been found in adult female rats (95). It can therefore be postulated that OT fibers are present at puberty and then disappear or that it is AVP that physiologically mediates these effects. It is known that AVP plays a role in the hippocampal activity-dependent plasticity mediated by V1aRs and V1bRs (89,96-99), and the use of high concentrations of agonists and antagonists in the above-mentioned studies does not rule out the possibility of overlapping V1aR/V1bR-mediated effects. Further studies are required to assess if OT has a direct effect on the activity-dependent synaptic plasticity involved in LTP and/or long-term depression (the neurobiological substrates of memory), or if it participates in learning and memory processes by acting on other neurotransmitters/neuromodulators.

\section{Critical Issues and Strategies}

On the basis of the reviewed literature, it is still too early to draw any definite conclusions concerning the role(s) of OT in regulating cognitive functions such as learning and memory for a number of reasons.

First of all, animal studies indicate that low doses of OT can improve memory in healthy subjects only when given during the first phase of consolidation (within 1 hour), but it has not yet been given to healthy humans during the consolidation phase and so no verification of a possible improving effect is possible.

Second, the cognitive effects of OT follow an inverted U-shaped dose-response curve that is typical of many peptides tested in animals, whereas studies of healthy humans have only tested single doses or a very narrow range of doses chosen on the basis of their ability to improve the recognition memory of faces. Future studies using a wider range of doses could provide more information about optimal OT doses for improving learning and memory.

Third, most human studies have used intranasally administered OT, which is the best noninvasive route for drugs that have poor systemic bioavailability after oral administration. However, nasal sprays are limited in terms of controlling dosing and absorption and consequently drug response (4). Furthermore, on the basis of recent data indicating that the detrimental social consequences of intranasal OT treatment in prairie voles persisted for much longer than the treatments themselves, we believe that caution is required when chronically administering intranasal OT to humans (44). Further animal studies are needed to examine doses, timing of administration, gender-related differences in efficacy, and the developmental timing of OT therapeutics. It is 
also worth remembering that interspecies differences in nasal cavity structures can limit the ability to extrapolate findings from animals to humans.

Finally, another very important issue is how OT affects cognition in normal and impaired subjects. Many drugs only enhance cognition in impaired animals and have no measurable effect (or even reduce performance) in normal rodents and nonhuman primates: no effect in a normal animal therefore does not necessarily preclude a beneficial effect in an impaired model (100). Studies of the effects of OT in animal models of neuropsychiatric disorders are urgently needed and could greatly aid the planning of clinical trials to investigate the hormone's potential benefits in humans with psychiatric disorders.

In conclusion, there are the premises for OT to become a successful pharmacologic treatment for patients with selected psychiatric and neurodevelopmental disorders. Learning how OT works in the brain will guide the transfer of its therapeutic potential from the laboratory to the clinic.

This work was supported by the Telethon Foundation Grant GGP12207 to BC.

The authors declare they have no biomedical financial interests or potential conflicts of interest.

Supplementary material cited in this article is available online at http://dx.doi.org/10.1016/j.biopsych.2013.08.029.

1. Bartz JA, Zaki J, Bolger N, Ochsner KN (2011): Social effects of oxytocin in humans: Context and person matter. Trends Cogn Sci 15: 301-309.

2. McCall C, Singer T (2012): The animal and human neuroendocrinology of social cognition, motivation and behavior. Nat Neurosci 15: 681-688.

3. Meyer-Lindenberg A, Domes G, Kirsch P, Heinrichs M (2011): Oxytocin and vasopressin in the human brain: Social neuropeptides for translational medicine. Nat Rev Neurosci 12:524-538.

4. Guastella AJ, MacLeod C (2012): A critical review of the influence of oxytocin nasal spray on social cognition in humans: Evidence and future directions. Horm Behav 61:410-418.

5. Gard PR, Naylor C, Ali S, Partington C (2012): Blockade of procognitive effects of angiotensin IV and physostigmine in mice by oxytocin antagonism. Eur J Pharmacol 683:155-160.

6. Gaffori OJ, De Wied D (1988): Bimodal effect of oxytocin on avoidance behavior may be caused by the presence of two peptide sequences with opposite action in the same molecule. Eur J Pharmacol 147:157-162

7. Bardou I, Leprince J, Chichery R, Vaudry H, Agin V (2010): Vasopressin/oxytocin-related peptides influence long-term memory of a passive avoidance task in the cuttlefish, Sepia officinalis. Neurobiol Learn Mem 93:240-247.

8. Davis JL, Pico RM, Cherkin A (1983): Dose-dependent and timedependent action of oxytocin on chick memory. Brain Res 266: 355-358.

9. Kovács GL, Bohus B, Versteeg DH, de Kloet ER, de Wied D (1979): Effect of oxytocin and vasopressin on memory consolidation: Sites of action and catecholaminergic correlates after local microinjection into limbic-midbrain structures. Brain Res 175:303-314.

10. Tomizawa K, Iga N, Lu YF, Moriwaki A, Matsushita M, Li ST, et al. (2003): Oxytocin improves long-lasting spatial memory during motherhood through MAP kinase cascade. Nat Neurosci 6:384-390.

11. Kovács GL, Vécsei L, Telegdy G (1978): Opposite action of oxytocin to vasopressin in passive avoidance behavior in rats. Physiol Behav 20: 801-802.

12. Bohus B, Kovács GL, de Wied D (1978): Oxytocin, vasopressin and memory: Opposite effects on consolidation and retrieval processes. Brain Res 157:414-417.

13. Boccia MM, Kopf SR, Baratti CM (1998): Effects of a single administration of oxytocin or vasopressin and their interactions with two selective receptor antagonists on memory storage in mice. Neurobiol Learn Mem 69:136-146.

14. Boccia MM, Baratti CM (2000): Involvement of central cholinergic mechanisms in the effects of oxytocin and an oxytocin receptor antagonist on retention performance in mice. Neurobiol Learn Mem 74:217-228.

15. Schultz H, Kovács GL, Telegdy G (1974): Effect of physiological doses of vasopressin and oxytocin on avoidance and exploratory behaviour in rats. Acta Physiol Acad Sci Hung 45:211-215.

16. de Oliveira LF, Camboim C, Diehl F, Consiglio AR, Quillfeldt JA (2007): Glucocorticoid-mediated effects of systemic oxytocin upon memory retrieval. Neurobiol Learn Mem 87:67-71.

17. Bohus B, Urban I, van Wimersma Greidanus TB, de Wied D (1978): Opposite effects of oxytocin and vasopressin on avoidance behaviour and hippocampal theta rhythm in the rat. Neuropharmacology $17: 239-247$

18. Burbach JP, Bohus B, Kovács GL, Van Nispen JW, Greven HM, De Wied D (1983): Oxytocin is a precursor of potent behaviourally active neuropeptides. Eur J Pharmacol 94:125-131.

19. de Wied D, Elands J, Kovács G (1991): Interactive effects of neurohypophyseal neuropeptides with receptor antagonists on passive avoidance behavior: Mediation by a cerebral neurohypophyseal hormone receptor? Proc Natl Acad Sci U S A 88:1494-1498.

20. Ibragimov RS (1990): Influence of neurohypophyseal peptides on the formation of active avoidance conditioned reflex behavior. Neurosci Behav Physiol 20:189-193.

21. Wu W, Yu LC (2004): Roles of oxytocin in spatial learning and memory in the nucleus basalis of Meynert in rats. Regul Pept 120: $119-125$.

22. deWied D (1984): Neurohypophyseal hormone influences on learning and memory processes. In: Lynch G, McGaugh JL, Weinberger NM, editors. Neurobiology of Learning and Memory. New York: Guilford Press, 289-321.

23. Gard PR, Daw P, Mashhour ZS, Tran P (2007): Interactions of angiotensin IV and oxytocin on behaviour in mice. J Renin Angiotensin Aldosterone Syst 8:133-138.

24. Nowakowska E, Kus K, Bobkiewicz-Kozłowska T, Hertmanowska H (2002): Role of neuropeptides in antidepressant and memory improving effects of venlafaxine. Pol J Pharmacol 54:605-613.

25. Kunchulia M, Bolkvadze T, Zhvania M, Kotaria N, Kiladze M (2010): Effects of oxytocin on behaviour and memory in rats subjected to chronic restrained stress. Georgian Med News 187:56-60.

26. Sahgal A (1986): Effects of peripherally injected pituitary peptides on recognition memory in pigeons. Regul Pept 1986 14:323-331.

27. Orłowska-Majdak M, Kolodziejski P, Traczyk WZ (2003): Centrally applied oxytocin has no effect on eyelid conditioning in rabbits. Endocr Regul 37:21-29.

28. Bartus RT, Dean RL, Beer B (1982): Neuropeptide effects on memory in aged monkeys. Neurobiol Aging 3:61-68.

29. McGraw LA, Young $\amalg$ (2010): The prairie vole: An emerging model organism for understanding the social brain. Trends Neurosci 33: 103-109.

30. Engelmann M, Wotjak CT, Neumann I, Ludwig M, Landgraf R (1996): Behavioral consequences of intracerebral vasopressin and oxytocin: Focus on learning and memory. Neurosci Biobehav Rev 20:341-358.

31. Popik P, Vetulani J, van Ree JM (1992): Low doses of oxytocin facilitate social recognition in rats. Psychopharmacology (Berl) 106: $71-74$

32. Arletti R, Benelli A, Poggioli R, Luppi P, Menozzi B, Bertolini A (1995): Aged rats are still responsive to the antidepressant and memoryimproving effects of oxytocin. Neuropeptides 29:177-182.

33. Popik P, Vetulani J, Van Ree JM (1996): Facilitation and attenuation of social recognition in rats by different oxytocin-related peptides. Eur $J$ Pharmacol 308:113-116.

34. Benelli A, Bertolini A, Poggioli R, Menozzi B, Basaglia R, Arletti R (1995): Polymodal dose-response curve for oxytocin in the social recognition test. Neuropeptides 28:251-255.

35. Popik P, Vetulani J (1991): Opposite action of oxytocin and its peptide antagonists on social memory in rats. Neuropeptides 18: 23-27.

36. Sala M, Braida D, Donzelli A, Martucci R, Busnelli M, Bulgheroni E, et al. (2013): Mice heterozygous for the oxytocin receptor gene $\left(\mathrm{Oxtr}^{+/-}\right)$show impaired social behaviour but not increased 
aggression or cognitive inflexibility: Evidence of a selective haploinsufficiency gene effect. J Neuroendocrinol 25:107-118.

37. Sala M, Braida D, Lentini D, Busnelli M, Bulgheroni E, Capurro V, et al. (2011): Pharmacologic rescue of impaired cognitive flexibility, social deficits, increased aggression, and seizure susceptibility in oxytocin receptor null mice: A neurobehavioral model of autism. Biol Psychiatry 69:875-882.

38. Windle RJ, Shanks N, Lightman SL, Ingram CD (1997): Central oxytocin administration reduces stress-induced corticosterone release and anxiety behavior in rats. Endocrinology 138: 2829-2834.

39. Ermisch A, Brust P, Kretzschmar R, Rühle HJ (1993): Peptides and blood-brain barrier transport. Physiol Rev 73:489-527.

40. Mens WB, Witter A, van Wimersma Greidanus TB (1983): Penetration of neurohypophysial hormones from plasma into cerebrospinal fluid (CSF): Half-times of disappearance of these neuropeptides from CSF. Brain Res 262:143-149.

41. Ludwig M, Tobin VA, Callahan MF, Papadaki E, Becker A, Engelmann M, Leng G (2013): Intranasal application of vasopressin fails to elicit changes in brain immediate early gene expression, neural activity and behavioral performance of rats. J Neuroendocrinol 25: 655-667.

42. Neumann ID, Maloumby R, Beiderbeck DI, Lukas M, Landgraf $R$ (2013): Increased brain and plasma oxytocin after nasal and peripheral administration in rats and mice. Psychoneuroendocrinology 38:1985-1993.

43. Chang SW, Barter JW, Ebitz RB, Watson KK, Platt ML (2012): Inhaled oxytocin amplifies both vicarious reinforcement and self reinforcement in rhesus macaques (Macaca mulatta). Proc Natl Acad Sci U S A 109:959-964.

44. Bales KL, Perkeybile AM, Conley OG, Lee MH, Guoynes CD, Downing GM, et al. (2013): Chronic intranasal oxytocin causes long-term impairments in partner preference formation in male prairie voles. Biol Psychiatry 74:180-188.

45. Ferguson JN, Aldag JM, Insel TR, Young LJ (2001): Oxytocin in the medial amygdala is essential for social recognition in the mouse. $J$ Neurosci 21:8278-8285.

46. Ferguson JN, Young LJ, Hearn EF, Matzuk MM, Insel TR, Winslow JT (2000): Social amnesia in mice lacking the oxytocin gene. Nat Genet 25:284-288.

47. McEwen BB (2004): The roles of vasopressin and oxytocin in memory processing. Adv Pharmacol 50:1-740.

48. Engelmann M, Ludwig M (2004): The activity of the hypothalamoneurohypophysial system in response to acute stressor exposure: Neuroendocrine and electrophysiological observations. Stress 7: 91-96.

49. De Vries GJ, Buijs RM (1983): The origin of the vasopressinergic and oxytocinergic innervation of the rat brain with special reference to the lateral septum. Brain Res 273:307-317.

50. Tribollet E, Charpak S, Schmidt A, Dubois-Dauphin M, Dreifuss JJ (1989): Appearance and transient expression of oxytocin receptors in fetal, infant, and peripubertal rat brain studied by autoradiography and electrophysiology. J Neurosci 9:1764-1773.

51. Engelmann M (2008): Vasopressin in the septum: Not important versus casually involved in learning and memory-two faces of the same coin? Prog Brain Res 170:389-395.

52. Tribollet E, Barberis C, Jard S, Dubois-Dauphin M, Dreifuss JJ (1988): Localization and pharmacological characterization of high affinity binding sites for vasopressin and oxytocin in the rat brain by light microscopic autoradiography. Brain Res 442:105-118.

53. Engelmann M, Wotjak CT, Ebner K, Landgraf R (2000): Behavioural impact of intraseptally released vasopressin and oxytocin in rats. Exp Physiol 85:125S-130S.

54. Popik P, Van Ree JM (1993): Social transmission of flavored tea preferences: Facilitation by a vasopressin analog and oxytocin. Behav Neural Biol 59:63-68.

55. Toth I, Neumann ID, Slattery DA (2012): Central administration of oxytocin receptor ligands affects cued fear extinction in rats and mice in a time point-dependent manner. Psychopharmacology (Berl) 223:149-158.

56. Beets I, Janssen T, Meelkop E, Temmerman L, Suetens N, Rademakers S, et al. (2012): Vasopressin/oxytocin-related signaling regulates gustatory associative learning in C. elegans. Science 338:543-545.
57. Timsit-Berthier M, Mantanus H, Geenen V, Adam F, Legros JJ (1988): Modifications of contingent negative variation (CNV) induced by oxytocin infusion. Neurophysiol Clin 18:501-511.

58. Ferrier BM, Kennett DJ, Devlin MC (1980): Influence of oxytocin on human memory processes. Life Sci 27:2311-2317.

59. Fehm-Wolfsdorf G, Bachholz G, Born J, Voigt K, Fehm HL (1988): Vasopressin but not oxytocin enhances cortical arousal: An integrative hypothesis on behavioral effects of neurohypophyseal hormones. Psychopharmacology (Berl) 94:496-500.

60. Bruins J, Hijman R, Van Ree JM (1992): Effect of a single dose of desglycinamide-[Arg8]vasopressin or oxytocin on cognitive processes in young healthy subjects. Peptides 13:461-468.

61. Heinrichs M, Meinlschmidt G, Wippich W, Ehlert U, Hellhammer DH (2004): Selective amnesic effects of oxytocin on human memory. Physiol Behav 83:31-38.

62. Rimmele U, Hediger K, Heinrichs M, Klaver P (2009): Oxytocin makes a face in memory familiar. J Neurosci 29:38-42.

63. Weigand $A$, Feeser $M$, Gärtner $M$, Brandt $E$, Fan $Y$, Fuge $P$, et al. (2013): Effects of intranasal oxytocin prior to encoding and retrieval on recognition memory. Psychopharmacology (Berl) 227: 321-329.

64. Herzmann G, Young B, Bird CW, Curran T (2012): Oxytocin can impair memory for social and non-social visual objects: a within-subject investigation of oxytocin's effects on human memory. Brain Res 1451:65-73.

65. Born J, Lange T, Kern W, McGregor GP, Bickel U, Fehm HL (2002): Sniffing neuropeptides: A intranasal approach to the human brain. Nat Neurosci 5:514-516.

66. Veening JG, Olivier B (2013): Intranasal administration of oxytocin: Behavioral and clinical effects, a review. Neurosci Biobehav Rev 37: 1445-1465.

67. McCulough ME, Churchland PS, Mendez AJ (2013): Problems with measuring peripheral oxytocin: Can the data on oxytocin and human behavior be trusted? Neurosci Biobehav Rev 37:1485-1492.

68. Bakermans-Kranenburg MJ, van ljzendoorn MH (2013): Sniffing around oxytocin: Review and meta-analyses of trials in healthy and clinical groups with implications for pharmacotherapy. Transl Psychiatry 3:e258.

69. Kéri S, Kiss I, Kelemen O (2009): Sharing secrets: Oxytocin and trust in schizophrenia. Soc Neurosci 4:287-293.

70. Rubin LH, Carter CS, Drogos L, Pournajafi-Nazarloo H, Sweeney JA, Maki PM (2010): Peripheral oxytocin is associated with reduced symptom severity in schizophrenia. Schizophr Res 124:13-21.

71. Feifel D, Macdonald K, Cobb P, Minassian A (2012): Adjunctive intranasal oxytocin improves verbal memory in people with schizophrenia. Schizophr Res 139:207-210.

72. Pedersen CA, Gibson CM, Rau SW, Salimi K, Smedley KL, Casey RL, et al. (2011): Intranasal oxytocin reduces psychotic symptoms and improves Theory of Mind and social perception in schizophrenia. Schizophr Res 132:50-53.

73. Arsenijevic Y, Dreifuss JJ, Vallet P, Marguerat A, Tribollet E (1995): Reduced binding of oxytocin in the rat brain during aging. Brain Res 698:275-279.

74. Parker KJ, Hoffman CL, Hyde SA, Cummings CS, Maestripieri D (2010): Effects of age on cerebrospinal fluid oxytocin levels in free-ranging adult female and infant rhesus macaques. Behav Neurosci 124: 428-433.

75. North WG, Harbaugh R, Reeder T (1992): An evaluation of human neurophysin production in Alzheimer's disease: Preliminary observations. Neurobiol Aging 13:261-265.

76. Mazurek MF, Beal MF, Bird ED, Martin JB (1987): Oxytocin in Alzheimer's disease: Postmortem brain levels. Neurology 37: 1001-1003.

77. Wierda M, Goudsmit E, Van der Woude PF, Purba JS, Hofman MA, Bogte H, Swaab DF (1991): Oxytocin cell number in the human paraventricular nucleus remains constant with aging and in Alzheimer's disease. Neurobiol Aging 12:511-516.

78. Dere E, Pause BM, Pietrowsky R (2010): Emotion and episodic memory in neuropsychiatric disorders. Behav Brain Res 215:162-171.

79. Pitman RK, Orr SP, Lasko NB (1993): Effects of intranasal vasopressin and oxytocin on physiologic responding during personal combat imagery in Vietnam veterans with posttraumatic stress disorder. Psychiatry Res 48:107-117. 
80. Acheson D, Feifel D, de Wilde S, McKinney R, Lohr J, Risbrough V (2013): The effect of intranasal oxytocin treatment on conditioned fear extinction and recall in a healthy human sample. Psychopharmacology (Berl) 229:199-208.

81. Altstein M, Gainer H (1988): Differential biosynthesis and posttranslational processing of vasopressin and oxytocin in rat brain during embryonic and postnatal development. J Neurosci 8:3967-3977.

82. Tyzio R, Cossart R, Khalilov I, Minlebaev M, Hubner CA, Represa A, et al. (2006): Maternal oxytocin triggers a transient inhibitory switch in GABA signaling in the fetal brain during delivery. Science 314:1788-1792.

83. Ceanga M, Spataru A, Zagrean AM (2010): Oxytocin is neuroprotective against oxygen-glucose deprivation and reoxygenation in immature hippocampal cultures. Neurosci Lett 477:15-18.

84. Crepel V, Aronov D, Jorquera I, Represa A, Ben-Ari Y, Cossart R (2007): A parturition-associated nonsynaptic coherent activity pattern in the developing hippocampus. Neuron 54:105-120.

85. Ben-Ari Y, Khalilov I, Kahle KT, Cherubini E (2012): The GABA excitatory/inhibitory shift in brain maturation and neurological disorders. Neuroscientist 18:467-486.

86. Kinsley CH, Trainer R, Stafisso-Sandoz G, Quadros P, Marcus LK, Hearon C, et al. (2006): Motherhood and the hormones of pregnancy modify concentrations of hippocampal neuronal dendritic spines. Horm Behav 49:131-142.

87. Leuner B, Caponiti JM, Gould E (2012): Oxytocin stimulates adult neurogenesis even under conditions of stress and elevated glucocorticoids. Hippocampus 22:861-868.

88. Bethlehem RA, van Honk J, Auyeung B, Baron-Cohen (2012): Oxytocin, brain physiology, and functional connectivity: A review of intranasal oxytocin fMRI studies. Psychoneuroendocrinology 38: 962-974.

89. Muhlethaler M, Charpak S, Dreifuss JJ (1984): Contrasting effects of neurohypophysial peptides on pyramidal and non-pyramidal neurones in the rat hippocampus. Brain Res 308:97-107.

90. Muhlethaler M, Sawyer WH, Manning MM, Dreifuss JJ (1983): Characterization of a uterine-type oxytocin receptor in the rat hippocampus. Proc Natl Acad Sci U S A 80:6713-6717.
91. Raggenbass M, Wuarin JP, Gahwiler BH, Dreifuss JJ (1985): Opposing effects of oxytocin and of a mu-receptor agonistic opioid peptide on the same class of non-pyramidal neurones in rat hippocampus. Brain Res 344:392-396.

92. Zaninetti M, Raggenbass M (2000): Oxytocin receptor agonists enhance inhibitory synaptic transmission in the rat hippocampus by activating interneurons in stratum pyramidale. Eur J Neurosci 12 : 3975-3984.

93. Ninan I (2011): Oxytocin suppresses basal glutamatergic transmission but facilitates activity-dependent synaptic potentiation in the medial prefrontal cortex. J Neurochem 119:324-331.

94. Lin YT, Huang CC, Hsu KS (2012): Oxytocin promotes long-term potentiation by enhancing epidermal growth factor receptormediated local translation of protein kinase Mzeta. J Neurosci 32: 15476-15488.

95. Knobloch HS, Charlet A, Hoffmann LC, Eliava M, Khrulev S, Cetin AH, et al. (2012): Evoked axonal oxytocin release in the central amygdala attenuates fear response. Neuron 73:553-566.

96. Chepkova AN, French P, De Wied D, Ontskul AH, Ramakers GM, Skrebitski VG, et al. (1995): Long-lasting enhancement of synaptic excitability of CA1/subiculum neurons of the rat ventral hippocampus by vasopressin and vasopressin (4-8). Brain Res 701: 255-266.

97. Ramanathan G, Cilz NI, Kurada L, Hu B, Wang X, Lei S (2012): Vasopressin facilitates GABAergic transmission in rat hippocampus via activation of $\mathrm{V}(1 \mathrm{~A})$ receptors. Neuropharmacology 63: 1218-1226.

98. Urban IJ (1998): Effects of vasopressin and related peptides on neurons of the rat lateral septum and ventral hippocampus. Prog Brain Res 119:285-310.

99. Chafai M, Corbani M, Guillon G, Desarmenien MG (2012): Vasopressin inhibits LTP in the CA2 mouse hippocampal area. PLoS One 7: e49708.

100. Floresco SB, Jentsch JD (2011): Pharmacological enhancement of memory and executive functioning in laboratory animals. Neuropsychopharmacology 36:227-250. 